\title{
Lessons From the Participants in Decolonising Research
}

\author{
Stuart Barlo \\ Gnibi Wandarahn, Southern Cross University \\ stuart.barlo@scu.edu.au
}

Keywords: decolonising research, yarning methodology, Indigenous Knowledge, participant controlled research

\begin{abstract}
This paper reflects on research undertaken as part of a Doctor of Philosophy, focusing on the restoration of contemporary Aboriginal men's dignity. These reflections centre on how the research participants began to train this researcher in decolonising research practices. Personal discovery and growth, as well as developing strong, ethical and reciprocal relationships, are core to doing decolonising research. Yarning as methodology and art as a method of communicating research are presented as ways of building such relationships and promoting personal transformation in research. Key lessons from this research are shared and demonstrate that for this researcher, the greatest act of decolonising research started with addressing his own mindset, which led to the realisation that Indigenous Australia no longer wishes to be studied or seen as requiring someone to lift them up.
\end{abstract}

\section{Introduction}

While it was memorable and exciting to complete doctoral research, and be awarded a PhD, it was the process that I found the most rewarding. Within this process there is a large portion of personal discovery that has developed my understanding of research. It was the involvement of the participants and their willingness to share their lives, their understanding of the topic being discussed and their ability to train me in ways of Aboriginal research that opened my eyes and heart along with the importance of providing information back to the various stakeholders in a way that is appropriate in each setting. The people who took part in the research project all understood research as a colonising process, as they had suffered through the process a number of times. Smith (2012) argues that from an Indigenous perspective research is seen as a "dirty word" because of their previous experiences (p. 1).

Mora and Diaz (2004) believe that the entire research endeavour must be participatory in nature to produce qualitatively different research that is based on community-identified problems and needs. I would add that it is important that the methods used to gather the data be suitable for and understandable to the people participating in the research project. This article will reflect upon three aspects of the journey associated with my PhD that demonstrate how the participants helped me decolonise the research process and empower individuals and their communities.

This article will encompass reflections on three research areas where the participants influenced my understanding of Indigenous research and the decolonising process. The areas involve lessons about the process and protocols associated with Aboriginal controlled 
research, the development of a normal method of communication that has been used for centuries by Aboriginal people (known generically as yarning) into an effective and validated research methodology, and the use of art as a method of reporting results and progress back to communities and participants.

Wilson (2008) has said that "If research doesn't change you as a person, then you haven't done it right" (p. 135). This is a yarn about how my research has changed me and the three major areas in which my research has impacted me. The first and probably the most profound was the way the participants gave themselves to the project and began training me in Aboriginal ways of conducting research.

\section{Lessons in Participant Controlled Research}

Each of the men began by volunteering to be a part of the project. The men who participated in the research project substantially took it upon themselves to train me in the art of conducting decolonised Indigenous research. They did this through many impromptu lessons that unfolded during our yarning sessions. It is important to mention that I had known all the Australian participants for many years prior to the research project and as it turned out, each of the men had a connection with each other that I was unaware of at the time the project started. In fact, I didn't become aware of this until the project was completed.

The first lesson came from someone I considered to be a dear friend and had known for 25 years. To set the scene, I live on the Far North Coast of NSW and my participant lives on the Far South Coast of NSW, approximately 18 hours away by car. After many emails and phone calls a date and time were set for our first yarning session. I had emailed the Elder the day I was leaving home to confirm that everything was still okay, and had received a reply stating that he was looking forward to my visit and was ready to be involved in the research. I arrived in town the day before the yarn, set up camp and let some friends know I was in town. Someone from the community told me he thought that the Uncle had left town that day and wouldn't be back for two days. I chose not to believe him because the emails stating that he was expecting me.

The following day I arrived at the appointed time and place only to find that the Elder was nowhere to be found. I phoned him and he told me that he needed to go to Canberra and would be back the following day so we arranged an alternative time for the following day. Again, I arrived at the appointed time and place only to find that he had just left and would not be returning that day. At this point I was beginning to think that he really didn't want to be a part of the project. I rang him later that day to give him every opportunity to withdraw if that's what he wanted. Again, he assured me that he was very interested in the project and wanted to be a part of it, so again we set an alternative time for the next day.

Once again, I turned up and the Elder was nowhere to be found. This time he had returned to town as he had an appointment that he had forgotten and had taken one of the children from the property with him so I knew that he needed to return. So, I waited for him. During this time, I convinced myself that he really didn't want to be a part of the research and these delays were his way of letting me know this, despite his assurances of the opposite.

When he did finally return he was smiling and ready to begin. Unknown to me, he had already set the fire and had a young man keeping the fire going while he was gone. The young man had been given instructions not to speak to me and that if I left he was to let the fire go out. I had seen this young man during the time I was waiting and thought that he was checking on me as he would appear then disappear. When he saw me sitting on a log waiting for him a smile came across Uncle's face and he said that this research must be important for me to wait three days 
to speak to someone who had demonstrated such unreliability. The Elder then took me to the place that he had prepared for us to have our yarns. The site holds special significance as it is where our Yuin Elders have in the past handed down some of their knowledge.

The Elder began to explain why he had delayed our meetings. He said,

that while I think that the project was very important, I need to know how important my involvement is to you and whether my involvement is important to the project or just easier to ask someone you have a relationship with. (Uncle Ossie Cruse, Personal communication, 20 July 2013)

He did go on to talk about how other researchers had asked him to be involved in their work, but only on their terms and at their convenience. For me, this encounter demonstrated how important it is to give our participants as much control over the process as possible. This encounter also helped me understand that the researcher does become part of the narrative. Additionally, as researchers, our behaviour can influence how our participants view the research and the information they are willing to share. With Western research the researcher controls the interview time, place and the type of information that is given. Uncle had given me an alternate understanding demonstrating a decolonising method, but the lessons did not end there.

To further emphasise these lessons another incident occurred during my second yarn with this Elder. We had been yarning for about an hour when for no apparent reason that I could see, he jumped to his feet and left stating the he would not allow me to change the rules associated with the yarning session without talking to him first. I was surprised by this as I was unaware that the rules had changed and followed him to ask what I had done that indicated that the rules were changing. He explained that in this type of formal yarning session the Elder is given total control of how the information is provided and in which direction the discussion headed; therefore, the Elder is treated with respect and is not interrupted or redirected.

At this point I need to provide some background to my relationship with this Elder. While he is my mentor and a senior Elder of my nation, the Yuin Nation, we have never been in this research setting before. The issue arose because I, as the researcher, had slipped back into a work colleague type of relationship, changing the power balance within the yarn. When we worked together I was in the position of responsibility requiring me to make decisions and elicit answers from my fellow workers of which this Elder was a member of the team. The Elder went on to take this opportunity to teach me about imparting important Aboriginal knowledge from an Elder's perspective. After he had explained how I was to behave during these times, we resumed the yarn.

A circumstance that involved another participant taught me a third lesson. I was yarning with an Elder and dear friend from the desert region of Australia. We had yarned for about two hours and had gone through all the ethics paper work prescribed by the university to give me permission to use his words/stories. A short while after the yarn had completed the Elder suddenly passed away. Neither his information nor my interpretations of what he had said had been checked, which is a vital aspect of maintaining accuracy and trustworthiness of the information. This raised a number of protocol issues culturally, personally and ethically.

From a cultural perspective after a death this information becomes part of the person's estate and is passed to his sons. Hence, I would need permission from the Elder's sons before I could use his yarns as his contribution to the research. This meant that a minimum of 12 months of sorry business would need to be concluded before I could approach the sons. I needed to decide whether his stories were necessary to be included. The wait to get permission would 
delay the conclusion of the research project for over a year and probably longer as relationships would need to be established both with me as the researcher and the research project itself.

From a personal perspective, this Elder's stories impacted me more than any of the others, and had set off a chain reaction within me that changed my way of thinking about dignity (the subject of my thesis) and became a personal filter for the stories that followed. Therefore, I believed that the information was important, and I also felt it needed to be shared as part of the research. From the perspective of Western academic ethics, I had all the permission I needed to go ahead and use the material collected from this Elder. It is often believed that research data belongs to the researcher or to the institution from which the researcher has come (Fishbein, 1991), therefore, once a participant has told the story, custodianship of that story now sits with the researcher. This created some personal turmoil. My understanding of Indigenous Knowledge systems firmly places the custodianship of the stories and the knowledge within them with the Elder who holds the knowledge, and there are strict protocols about who can share the information. This case exemplified that simply because the information was shared with me, did not give me the right to share the information as I wished.

I searched the literature concerning ownership of research data. A university's perspective is that the data belongs to the university and they have the right to request the information and apply it to a different context (Fishbein, 1991, pp. 129-130; SCU Research Responsible Conduct Policy, ND). In this description, there was no mention of the participants. Sieber and Stanley (1988) indicate that the source of the data is not even considered in questions of ownership or custodianship.

After conversations with the other participants about this situation, it was decided that I needed to remove the content of the discussions with that Elder from the thesis and I should also strictly adhere to the protocols associated with sorry business applicable to his nation group so that the Elder could be honoured according to cultural norms and his family could be left in peace. It was also decided that the research should continue without delay as the other Elders who were participating thought that the topic was too important to not be discussed. This lesson taught me the importance of respecting knowledge and its custodians. I was also taught that as a researcher I have a particular role and responsibility in how I receive the knowledge and then transmit what has been revealed.

One of the most significant acts of decolonisation came when I started to explain to the participants that their names were not going to be used within my thesis. I had explained that this was normal practice and a way of protecting the participants from any backlash that may or may not come from the research (Crow \& Wiles, 2008). Following this explanation one to the participants became upset and began to tell me how as a child he had been placed in a boys' institution where on his arrival he was given a number and while he remained at the institution he was referred to by that number and never by his name. He said that this made him and the other residents feel as if they were nobody and of no value. He then went on to tell me that the home had a dog and that the dog had a name. He added that he can still remember his number and the dog's name. While it is common practice for researchers to de-identify their research, particularly in Indigenous research, this practice is seen by many Indigenous participants as the continuation of the colonisation process. All of my participants requested that their voice be restored in my thesis. At this request, I returned to the SCU ethics committee and submitted a variation request to my research ethics approval. This request stimulated some conversation around whether or not the participants really understood that they would be identified as being part of the research and what this really meant. After I relayed this story, approval was granted. A decolonising aspect of this research was to give the power of the information back to its owners through allowing their voices to be heard as the knowledge holders. 
These lessons developed during the progression of yarning in the collection of data. However, more than was expected was discovered out of this method and added a new dimension to my research. This lead to the second area of my learning in the research. Over the time of the research the yarning process developed into a methodology.

\section{Lessons in Yarning as Methodology}

A methodology is a concept that contains a defined set of principles. It is these principles that provide the theoretical framework that sets the foundation for the chosen methods that will be utilised in a research project. It is this framework that provides a stabilising influence for the process of analysis and also provides a structure to test the validity of knowledge collection methods. There is a very strong ontological foundation behind the yarning method that supports understanding it as a methodology. Whether it is within a Canadian First Nation talking circle or an Australian Aboriginal yarning circle, there are ancient protocols that dictate behaviour. These protocols flow from the ancestors and are passed down to the individuals through the discussions that take place over a lifetime (Aunty Barb Big-Canoe-McDonald, 2014; Uncle Larry Kelly, 2012).

During one of the yarning sessions an Elder explained the yarning space from his perspective. He said that the yarning space is a protected space. Yarning was the chosen method of data collection as this concept has thousands of years of history as a communication tool within Indigenous culture. The power of yarning as a decolonising tool comes when yarning is understood as not only a research method, but also as a research methodology. Culture has always enabled men and women to interact with one another in many ways; they can sing, dance or play together with little difficulty. This ability to communicate together about subjects that matter deeply to them, however, seems invariably to lead to dispute (Bohm, Factor, \& Garrett, 1991). Indigenous people have utilised yarning as a workable method to share, explore and learn since the dreaming and will continue to do so (Dean, 2010). Yarning reflects a process of sharing knowledge that is reliant upon relationships, expected outcomes, responsibility and accountability between the participants (Bessarab, 2012; Bessarab \& $\mathrm{Ng}$ 'andu, 2010). Moreover, yarning can take on many different forms and structures, allowing it to be as diverse as the many Aboriginal nations that utilise it within Australia (Bessarab, 2012; Bessarab \& Ng'andu, 2010; Dean, 2010). The idea of yarning is simply an extension of the story telling tradition which has been part of the Aboriginal oral tradition for thousands of years (Neidjie, 2002). The telling of stories is used to teach children what is expected of them and how they are to behave in certain situations. Stories are also used to hand down and impart information. Bessarab (2012) states that "stories formed part of the Aboriginal cosmology; the dreaming stories informed people of how the world was created, set the protocols for behaviour and outlined responsibilities" (p. 22).

The term yarning is used as a 'one stop shop' to explain a multilayered and multifaceted way of cultural expression. Dean (2010) points out that there a many layers or types of yarns that range from a simple conversation between friends in an informal situation, to a setting where it is time to impart cultural knowledge by an Elder. Therefore, yarning can range from a group of friends sitting around a camp fire having a conversation, telling jokes and sharing stories, through to an Elder calling you aside into a formal setting where important cultural knowledge is handed down (Dean, 2010). These times are very formal and have ritual and ceremony attached to them. It is in the space between these two positions where research is conducted and where the knowledge holder has complete control and directs how knowledge can be shared. 
This method will be referred to as yarning (Dean, 2010; Wilson, 2001, 2008b) and comes from a style of storytelling employed by Aboriginal communities when the intention is the impartation of information to the listeners (D Bessarab \& Ng'andu, 2010; Martin, 2003, 2008; Sandelowski, 1991). It is based on relationship and respect. In addition, the participant is provided with a culturally safe space in which to provide his/her story. In some circles, yarning is considered to be similar in its approach to the interview method known as in-depth interviews or unstructured interviews (Kohn \& Dipboye, 1998; Minichiello, Aroni, \& Hays, 2008; Minichiello, Aroni, Timewell, \& Alexander, 1990). However, it really is very different and requires a specific set of skills that include a respect for the process and the protocols that govern it.

The yarning space is protected by seven principles and six protocols that come together to protect and enhance the yarning space. The principles are reciprocity, respect, responsibility, dignity, equality, integrity and self-determination. The protocols that are associated with each yarning space are as follows: the space is gender sensitive, it is inclusive, there is a gift within each one, each person has an opportunity to speak, the participants are in control of the yarning space and there is freedom within the space. The Elder with whom I was working emphasised the importance of these principles and protocols.

This protection allows the participants to bring their history, their ideas and any information that they wish to impart. I realised that the Aboriginal concept of yarning, as not only a data collecting method but as research methodology, had not been heard of, let alone considered by my university prior to my ethics application. This application sparked a conversation on the feasibility of using yarning to formally conduct research among Indigenous peoples. The power of yarning as a decolonising tool comes when yarning is understood as not only a research method but as a research methodology.

Over the last decade there have been a number of articles on yarning and it how works. There is a growing recognition that Indigenous communities have utilised yarning as a workable method to share, explore and learn for many previous generations and that they will continue to do so (Bessarab, 2012; Bessarab \& Ng'andu, 2010; Dean, 2010). Yarning reflects a formal process of sharing knowledges that is reliant upon relationships, expected outcomes, responsibility and accountability between the participants, country and culture. This process is valued by many other Indigenous nations. From the perspective of my university's ethics committee, one of the difficulties with yarning is that it can take many forms and structures, allowing it to be as diverse as the many Aboriginal nations that utilise yarning (Dean, 2010). From my perspective, as an Indigenous researcher, Indigenous research should reflect the authority and foundations of Indigenous Knowledge systems and yarning as a methodology can permit this.

Yarning is not only a data collection method. As a principle-based research methodology, it allows Indigenous worldviews to come to the fore in the research context. It also provides a culturally safe place for the knowledge to be shared and a culturally appropriate lens with which to analyse the information that has been shared.

Because yarning, as a research methodology, is framed by a body of principles, protocols and practices developed by Indigenous Elders, Indigenous Knowledge about the world is established as valid and trustworthy in an academic environment. This enables some aspects of traditional Indigenous Knowledge to be made known to wider communities. This methodology systemically advances the teaching, research, and practices of Indigenous Knowledge through rigorous inquiry that allows interaction to empower participants through a culturally safe and ethical research method. As mentioned earlier, yarning has a rich body of protocols, principles and practices that mandate how you should and should not behave during a yarning session thus leading to this culturally safe and ethical research method. 
Yarning is therefore one of the most powerful tools used in the battle to decolonise Indigenous research. While yarning is often seen as a type of oral communication and is generally viewed as limited to this arena, this is far from the truth. Yarning does actually incorporate drawing, dance and singing. Yarning can be utilised as a tool for decolonising due to the fact that as a research methodology, it is based entirely in an Indigenous paradigm. It takes into account the relationships associated with the knowledge, the context that knowledge is found in and the participants as the knowledge caretakers. This brings me to the third lesson, where I learned about the decolonisation of research through the use of art to communicate research.

\section{Art in Research}

The third aspect of my learning about yarning as a decolonising tool, was its power to incorporate the medium of art as a way of illustrating the yarns (Bochner \& Ellis, 2003; Leavy, 2017) and as a gift (Boydell, Gladstone, Volpe, Allemang, \& Stasiulis, 2012). This seemed to be natural progression. Early in the research process it was suggested that I start using art to reflect on what was said during the yarning sessions. At first, I was reluctant to engage with this medium, but being a visual thinker myself, I agreed with this suggestion. The original purpose of the art was to help me to understand the concepts that were starting to come forward as part of the research. McNiff (2008) acknowledges this as an important concept in art-based research, stating that "artistic expressions in all of the different forms of the arts [offer] a primary way of understanding and examining experience by both researchers and the people that they involve in their studies" (p. 29).

There is a strong connection between art and research (Bochner \& Ellis, 2003; Eisner, 2008). This visual representation of concepts allows an opportunity to provide a pictorial understanding of the research (Boydell et al., 2012; Leavy, 2015, 2017). This concept became apparent after showing one of the participants a couple of the drawings I had made after his yarning session. His understanding of the research went to a higher level and his willingness to share became stronger. He stated that he could see his stories in the drawings and he could see where he fitted into the research (Uncle Larry Kelly, Personal communication, 15 September 2014).

Over the length of the project, there were 20 individual pieces of art produced that became a very important part of returning the research back to communities (Boydell et al., 2012) in the form of a book. A second purpose for this art developed in relation to the the wider community; this book became an example of how research can be illustrated and presented to Aboriginal communities in a culturally appropriate way where they are able to quickly identify an understanding of the research.

Traditional artwork has been used for thousands of years to communicate many different things, ranging from a simple map of the surrounding country to detailed information about how the culture itself functions on many levels. Elders have often used simple sand drawings or carvings on rocks and trees to provide educational opportunities for the communities and people around them. While in Newman, Western Australia, I witnessed a scene where an Elder was sharing a story with the people around him by drawing on the ground with his finger to emphasise various parts of the story. This form of iconography is often used to tell stories where words are insufficient. Artwork can also be used as a form of introduction such as that on message sticks.

The use of art has developed in two directions within qualitative research. First as a way of conducting research using art known as art-based research (Riddett-Moore \& Siegesmund, 2012). Secondly, art is used to disseminate research results and knowledge that flows from the research (Boydell et al., 2012). Boydell et al. (2012) describe art in research as a way 
of highlighting the complexities and multidimensionality involved in understanding of new knowledge. Boydell (2011) explains knowledge translation as harnessing that potential and bridging the gap between what we know and what we do. The way the artwork is used in my thesis is to aid in the distribution of the knowledge gained from the Elders involved in the yarning sessions. Each piece of artwork has an explanation in English attached to it so people have a choice to hear the message from the artwork or through simply reading the explanations.

The effectiveness of this style of communication was demonstrated when a draft copy of the art book was taken to the Northern Territory and shown to a Jawoyn Elder. This Uncle was simply handed the book without any explanation and he was able to read the information presented in pictorial form, giving him an understanding of my thesis, the research methodology and the results. With great excitement, he took the book to the Land Council office and requested that all future reports based on research conducted in his community be presented in this format.

The effectiveness of this type of communication has also been affirmed by a number of nonIndigenous people who have seen the artwork and have expressed gratitude for having the opportunity to see research presented in this form. They have asked about the availability of the book in libraries and commented that their knowledge about Aboriginal people was increased through seeing the book and some have expressed the personal and emotional impact on them. This is testimony to the value of this research presentation method.

\section{Conclusion}

The three aspects described in this article demonstrate that if a researcher is prepared to take their time and listen to the Indigenous communities, they can start the process of decolonising their own research and create a positive narrative among Indigenous communities in contact with research. It is important for researchers to understand that these communities do not need them as their lives will go on regardless; it is the researchers who need these communities to partner with them in the research endeavour. The lessons I learned from the participants during and at the end of the research demonstrated that decolonising methodologies and methods are necessary for successful Indigenous research. The Elders demonstrated to me that the greatest act of decolonising research starts with the mindset of the individual researcher with the realisation that Indigenous Australia no longer wishes to be studied or seen as requiring someone to lift them up. What is needed is someone to walk beside them as equal partners. It is these types of partnerships that are needed for greater progress to be made. 


\section{References}

Bessarab, D. (2012). Yarning: A culturally safe method of Indigenous conversation. Paper presented at the Dementia Networking Seminar, Bentley, Western Australia.

Bessarab, D., \& Ng'andu, B. (2010). Yarning about yarning as a legitimate method in Indigenous research. Journal of Critical Indigenous Studies, 3(1), 37-50.

Bochner, A. P., \& Ellis, C. (2003). An introduction to the arts and narrative research: Art as inquiry. Qualitative inquiry, 9(4), 506-514.

Boydell, K. M. (2011). Making sense of collective events: The co-creation of a research-based dance. In I. Graham (Ed.), Knowledge to Action: An End-of-Grant Knowledge Translation Casebook (pp. 5-9). Ottawa, ON: Canadian Institutes of Health Research.

Boydell, K. M., Gladstone, B. M., Volpe, T., Allemang, B., \& Stasiulis, E. (2012). The Production and Dissemination of Knowledge: A Scoping Review of Arts-Based Health Research. Forum Qualitative Sozialforschung / Forum: Qualitative Social Research in Nursing \& Health, 13(1).

Boydell, K. M., Gladstone, B. M., Volpe, T., Allemang, B., \& Stasiulis, S. (2012). The production and dissemination of knowledge: A scoping review of arts-based health research. Forum Qualitative Sozialforschung/Forum: Qualitative Social Research, 13(1). Retrieved from FQS - Forum: Qualitative Social Research website: http://www.qualitative-research.net/

Crow, G., \& Wiles, R. (2008). Managing anonymity and confidentiality in social research: the case of visual data in Community research. NCRM Working Paper Series. ESRC National Centre for Research Methods. E.S.R.C Economic \& Social Research Council. Retrieved from www.ncrm.ac.uk

Dean, C. (2010). A yarning place in narrative histories. History of Education Review, 39(2), 6-13.

Eisner, E. (2008). Art and knowledge. In J. G. Knowles \& A. L. Cole (Eds.), Handbook of the arts in qualitative research (pp. 3-12). Thousand Oaks: Sage Publication, Inc.

Fishbein, E. A. (1991). Ownership of research data. Academic Medicine, 66(3), 129-133.

Kohn, L. S., \& Dipboye, R. L. (1998). The effects of interview structure on recruiting outcomes. Journal of Applied Social Psychology, 28(9), 821-843.

Leavy, P. (2015). Method meets art: Arts-based research practice (2 ed.). New York: Guilford Publications.

Leavy, P. (2017). Introduction to Arts-Based Research. In P. Leavy (Ed.), Handbook of Arts-based Research (pp. 3 -21). New York: The Guilford Press.

Martin, K. L. (2003). Ways of Knowing, Ways of Being and Ways of Doing: a theoretical framework and methods for Indigenous re-search and Indigenist research. Voicing Dissent, New Talents 21C: Next Generation Australian Studies. Journal of Australian Studies, 76, 203-214.

Martin, K. L. (2008). Please knock before you enter Aboriginal regulation of Outsider and the implications for researchers. Teneriffe, Qld: Post Press.

McNiff, S. (2008). Art-based research. In J. G. Knowles \& A. L. Cole (Eds.), Handbook of the arts in qualitative research (pp. 29-40). Thousand Oakes: Sage Publications.

Minichiello, V., Aroni, R., \& Hays, T. (2008). In-depth interviewing: Principles, techniques, analysis (3 ed.). Sydney: Pearson Education Australia.

Minichiello, V., Aroni, R., Timewell, E., \& Alexander, L. (1990). In-depth interviewing: Researching People. Sydney: Longman Cheshire. 
Mora, J., \& Diaz, D. (Eds.). (2004). Latino social policy: A participatory research model (1 ed.). New York: Haworth Press.

Neidjie, B. (2002). Gagudju Man. Marleston: J B Books Pty Ltd.

Riddett-Moore, K., \& Siegesmund, R. (2012). Arts-based research: Data are constructed, not found. In S. R. Klein (Ed.), Action Research Methods (pp. 105-132). New York: Palgrave Macmillan.

Sandelowski, M. (1991). Telling stories: Narrative approaches in qualitative research. Journal of Nursing Scholarship, 23(3), 161-166.

SCU Research Responsible Conduct Policy. (ND). Higher Degrees Research. Southern Cross University Lismore. Retrieved from https://policies.scu.edu.au/view.current.php?id=00099\#min18

Sieber, J. E., \& Stanley, B. (1988). Ethical and professional dimensions of socially sensitive research. American Psychologist, 43(1), 49-55. doi:10.1037/0003-066X.43.1.49

Smith, L. T. (2012). Decolonizing Methodologies Research and Indigenous Peoples (2 ed.). New York: Zed Books.

Wilson, S. (2001). What is indigenous research methodology? Canadian Journal of Native Education, 25(2), 175-179.

Wilson, S. (2008). Research is ceremony: Indigenous research methods. Halifax \& Winnipeg: Fernwood Publishing. 